\title{
Marx diante da crise do capital
}

\author{
Marx ahead of the capital's crisis
}

\section{Jadir Antunes}

Doutor em Filosofia e professor do Programa de Mestrado em Filosofia da Unioeste, Toledo, PR - Brasil, e-mail: jdiant@yahoo.com.br

\section{Resumo}

Este artigo tem por objetivo comentar a concepção de Marx sobre o problema da crise na sociedade capitalista. As chamadas teorias causais procuram mostrar que em Marx haveria uma causa central para a explicação da crise. Entre essas diversas causas estariam a anarquia do mercado, a superprodução, o subconsumo, a queda tendencial da taxa de lucro, a desproporção intersetorial, a renovação periódica do capital fixo e a superacumulação de capitais. As teorias causais buscam, de modo geral, compreender o movimento cíclico da crise, ou seja, o seu ordenamento empírico e causal. Não concordamos que uma leitura causal do problema possa ser considerada o melhor caminho para se entender o tema da crise. Ao se cair nessa forma de explicação fica-se refém de uma teoria dos ciclos econômicos e da tentativa de se ordenar os movimentos empíricos desses ciclos, esquecendo-se do caráter dialético e programático de $O$ capital.

Palavras-chave: Karl Marx. Teoria da crise. Capitalismo. 


\section{Abstract}

This article intends to comment the Marx's conception about the problem of crisis in the capitalist society. The called causal theories look to show that in Marx would have a central cause of crisis. Among these diverse causes they would be the market's anarchy, the overproduction, the underconsumption, the tendencial decrease of average profitrate, the intersectorial disproportionality, the periodic renewal of fixe capital and overaccumulation of capital. The causal theories search, in general way, to understand the cyclical movement of crisis, that is, its empirical and causal order. We do not agree that a causal reading of the problem can be considered the better way to understand the subject of crisis. This explanation form is a theory of the economics cycles and an attempt to order the empirical movements of these cycles. This understand form forget the dialectic and programmatic character of Capital.

Keywords: Karl Marx. Theory of crises. Capitalism.

\section{Introdução}

Este artigo tem por objetivo comentar a concepção de Marx sobre o problema da crise na sociedade capitalista. De modo geral, a bibliografia sobre o tema da crise tem girado em torno de dois problemas: o de precisar suas causas e o de prognosticar as tendências futuras do desenvolvimento capitalista. As chamadas teorias causais procuram mostrar que em Marx haveria uma causa central para a explicação da crise. Entre essas diversas causas estariam a anarquia do mercado, a superprodução, o subconsumo, a queda tendencial da taxa de lucro, a desproporção intersetorial, a renovação periódica do capital fixo e a superacumulação de capitais. As teorias causais buscam, de modo geral, compreender o movimento cíclico da crise, ou seja, o seu ordenamento empírico e causal.

Os diferentes intérpretes do tema em Marx que se apoiam na noção de causa escolhem geralmente uma passagem específica de O capital para provar seus argumentos em favor de uma causa central e determinante para a crise. Os partidários da desproporcionalidade entre os diferentes departamentos da produção e da anarquia como 
causas centrais da crise, por exemplo, escolhem geralmente a III Seção do Livro II, na qual Marx analisa o problema da reprodução social do capital global. Já os partidários da queda da taxa de lucro como causa central escolhem a III Seção do Livro III, em que Marx estuda o problema da lei da queda tendencial da taxa de lucro.

Não concordamos que uma leitura causal do problema possa ser considerada o melhor caminho para se entender o tema da crise. A categoria de causa é uma categoria das chamadas filosofias do entendimento, das filosofias que negam a possibilidade do pensamento apreender a totalidade do mundo e a existência de um nível da realidade oculto aos nossos sentidos, que transcende o nível imediato da realidade sensível e corpórea.

Como sabemos, causa é tudo aquilo que vem primeiro. Assim, ela implica necessariamente o uso da categoria de efeito. O efeito é aquilo que vem segundo. Nesse sentido, a causa antecede no tempo o efeito. Uma casa sempre engendra a necessidade de se encontrar uma causa anterior. Desta busca, surge um ciclo vicioso e infindável de causas e para encerrá-lo é necessário supor, arbitrariamente, uma causa primeira. Essa natureza arbitrária da categoria de causa conduz o pensamento, assim, à divergência e à falta de unidade. Uma análise causal só pode, por isso, ser uma análise dos ciclos econômicos e seus encadeamentos empíricos, onde a crise aparece como o efeito de certas causas (da superprodução, do subconsumo, da queda da taxa de lucro e assim por diante).

Uma análise correta do problema da crise deve se apoiar no uso de categorias dialéticas - de categorias como possibilidade, realidade, fundamento, fenômeno, modo de expressão ou de manifestação -, largamente utilizadas por Marx em $O$ capital. A causa não é apenas aquilo que vem antes, mas é, ainda, aquilo que desaparece no efeito. Uma vez dada certa causa, ela desaparece no efeito. As categorias dialéticas, porém, não desaparecem uma após a outra, mas, ao contrário, elas se fundem e se misturam entre si sem se dissolverem durante seu desenvolvimento. A possibilidade não desaparece com a realidade nem o fundamento com o fenômeno. Em $O$ capital, todas essas categorias estão intimamente relacionadas entre si no conceito de crise, conduzindo o pensamento, assim, à unidade e à certeza teórica. 
Em nosso livro: $\mathrm{O}$ movimento dialético do conceito de crise em $\mathrm{O} \mathrm{Ca}$ pital de Karl Marx, lançado em autoria com Hector Benoit em fevereiro de 2009 pela Editora Týkhe, procuramos esclarecer essa questão em $O$ capital. Procuramos esclarecer ali a existência de uma teoria dialética, unitária e sistematizada de Marx sobre o problema da crise que se estende ao longo dos três livros de $O$ capital, e sua relação com o colapso do sistema capitalista e a teoria da revolução socialista. Em nosso livro, procuramos mostrar que a chamada teoria da crise não pode ser compreendida como um tema a parte e separado de outros temas de $O$ capital. Ao se cair nessa forma de entendimento fica-se refém de uma teoria dos ciclos econômicos e da tentativa de se ordenar os movimentos empíricos desses ciclos, esquecendo-se do caráter político e programático de $O$ capital.

Neste artigo, dado seus limites, propomo-nos analisar o ponto de vista não causal de Marx sobre três elementos importantes da crise em $O$ capital: a superprodução, o subconsumo e a queda tendencial da taxa média de lucro. Em O capital a teoria da crise não se identifica com a teoria dos ciclos econômicos, ela se identifica, sim, com a própria noção de capital - objeto de todos os três longos livros. Assim, uma concepção dialética, e não causal, sobre a crise deveria partir da análise de suas possibilidades mais gerais e abstratas - contidas já na primeira seção do livro primeiro - para sua conversão em ato - conversão realizada no livro terceiro com a exposição da concorrência e suas determinações, e a autodestruição inevitável do sistema.

Em Marx, a teoria da crise é inseparável da leitura do conjunto dos três livros de $O$ capital e da teoria da revolução socialista. Por isso, acreditamos que a teoria da crise se identifica com a teoria do colapso inevitável do conjunto do sistema, ainda que esse colapso não resulte necessariamente em uma revolução socialista. O colapso é inevitável porque as contradições que fundamentam a produção capitalista permanecem cada vez mais explosivas e insolúveis no interior do sistema e, na ausência de uma solução positiva - a revolução socialista -, essas contradições vão lentamente se acumulando e destruindo as forças produtivas já desenvolvidas e lançando o conjunto do sistema na barbárie e na indefinição caótica do futuro. 


\section{As possibilidades formais da crise}

Marx (1980), em sua crítica às concepções de Ricardo sobre a acumulação de capital, fala da crise em estado potencial (Krise potentia), das formas abstratas da crise real (abstrakte Formem der wirklichen Krise), de elemento de crise (Element der Krise), de propensões à crise (Anlagen der Krisen) e da possibilidade desenvolvida ou forma abstrata da crise (Möglichkeit oder abstrakte Form der Krise). Fala ainda da forma específica da crise monetária, da possibilidade geral da crise (die allgemeine Möglichkeit der Krise), das condições gerais da crise (die allgemeinen Bedingungen der Krise) e da forma mais geral da crise (die allgemeinste Form der Krise).

Como o capital aparece inicialmente em seu processo de valorização transformando dinheiro em mercadoria (D-M) e mercadoria em mais dinheiro $\left(\mathrm{M}-\mathrm{D}^{\prime}\right)$, como ele aparece inicialmente como mercadoria e dinheiro é aí, na instância das trocas, que surgem, na análise de Marx, as primeiras possibilidades de crise. Essas primeiras possibilidades estão determinadas pela necessidade, intrínseca à mercadoria, de metamorfosear sua forma natural na forma fluída do dinheiro e do risco que corre o processo de valorização do valor se essa metamorfose não se realizar.

Mas a possibilidade de compra e venda se dissociarem no tempo e no espaço - possibilidade visível já nessa instância mais aparente do capital - anuncia apenas a possibilidade mais geral da crise e, por isso, também, a forma mais abstrata dela. Nessa instância, diz Marx (1980, p. 947), "aparece a existência da crise em suas formas mais simples e em seu conteúdo mais simples, até onde a própria forma é seu conteúdo mais simples. Mas ainda não é conteúdo com fundamento concretizado (kein begründeter Inhalt)". Essas formas sozinhas, diz Marx (1980, p. 947), "não podem explicar por que desvelam sua face crítica, por que a contradição potencial (potentia Widerspruch) nelas contida se patenteia contradição em ato (actu Widerspruch)".

A análise das determinações da crise deve, portanto, avançar para além da instância aparente das trocas e seguir para a instância mais concreta e determinada das relações entre capital e força de trabalho presentes no mundo nada luminoso e fantasmagórico da produção, 
ou seja, a análie deve seguir para a instância onde capital e trabalho não se defrontam meramente como compradores e vendedores de força de trabalho, como meros possuidores de mercadorias, mas, sim, como capitalistas e operários.

Quando abandonamos a análise da esfera da circulação simples de mercadorias, em que impera a aparência da troca de equivalentes instância essa onde não aparece e, inclusive, se oculta o verdadeiro processo de intercâmbio desigual entre capital e trabalho -, e adentramos na esfera da produção, que é, simultaneamente, a esfera onde se realiza o consumo da força de trabalho, surgem então novas determinações que ajudam a desvelar o verdadeiro fundamento da crise.

\section{0 problema da superprodução e do subconsumo}

Para a existência do capital é fundamental, por um lado, a existência de uma classe de trabalhadores plenamente livres. Livres de tudo, inclusive dos meios de subsistência necessários para manter vivo um homem e sua família. Uma classe que, por não ser proprietária dos meios de produção para o trabalho, e nem, muito menos, dos meios de subsistência necessários para manter-se viva, esteja obrigada a vender-se diariamente no mercado para o capital. De outro lado, é necessária não apenas uma classe compradora dessa força de trabalho e detentora exclusiva dos meios de produção e subsistência, é necessário, ainda, que essa classe compradora de força de trabalho não a compre meramente para satisfazer suas necessidades pessoais sejam essas necessidades oriundas do estômago ou da fantasia. É necessário que essa classe de compradores contrate força de trabalho para satisfazer, sim, as insaciáveis necessidades do capital por mais sobretrabalho, por mais-valia, por riqueza em sua forma genérica e abstrata, por riqueza não em forma de coisas e valores de uso, mas de riqueza sob a forma de dinheiro, por essa forma de riqueza que não possui sua finalidade no consumo, mas, sim, por essa forma que possui uma finalidade em si mesma, da riqueza sem-fim que é o valor de troca. 
Para que as necessidades insaciáveis do capital - do qual o capitalista é uma mera personificação - possam se realizar é fundamental que não apenas a classe dos produtores diretos, a classe operária, seja mantida forçosamente em um nível de consumo muito baixo, mas é ainda fundamental que também a classe dos capitalistas, a classe dos funcionários do capital, mantenha seu nível de consumo sob limites muito estreitos, ainda que esses limites sejam muito superiores aos limites impostos à classe operária, e converta, assim, continuamente, a maior parte da sua mais-valia em capital e não em renda para consumo pessoal.

Ou seja, para que o processo de valorização do capital possa ocorrer incessantemente sob escalas cada vez mais crescentes, é fundamental que seu funcionário, o capitalista, divida a mais-valia em uma parte sempre maior absoluta e relativamente em capital e outra parte, sempre menor relativamente, em renda para seu usufruto próprio. Se os capitalistas não atuassem na produção como agentes do capital, como agentes da produção, mas, sim, como agentes do consumo, não poderia haver superprodução, pois não haveria sentido continuar a produção após satisfeitas as necessidades do estômago e da fantasia dessa classe. Contudo, aí não haveria evidentemente capitalismo.

Isso significa dizer que ainda que o capitalista individual possa ampliar sua massa absoluta de consumo, o conjunto da classe capitalista está obrigado, pela lógica da acumulação de capital, a refrear seus próprios instintos consumistas em nome do consumo reprodutivo do ser-capital. O capitalista individual pode aumentar sua massa absoluta de consumo ano após ano, sem que aumente na mesma escala e sentido a massa de consumo da classe capitalista, porque na lógica da acumulação a crescente ampliação da massa absoluta da riqueza é acompanhada por uma cescente centralização do capital em mãos de um número cada vez menor de capitalistas individuais.

O problema da superprodução e do subconsumo não possui, por isso, explica Marx, nenhuma relação com as medidas absolutas de consumo das classes, com o grau mais elevado ou mais baixo absolutos de consumo. O problema da superprodução, do excesso de mercadorias que abarrotam o mercado sem compradores, o problema de sua medida, diz respeito unicamente ao grau de consumo relativo das classes 
diante do grau de expansão absoluto da produção. Não diz respeito ao grau mais baixo ou mais alto de consumo da classe operária e dos capitalistas, se estes estão consumindo absolutamente mais ou menos que antes da crise, se estão vivendo (e consumindo) melhor ou pior que antes da superprodução, mas diz respeito, sim, se a taxa de crescimento absoluto desse consumo cresce ou não na mesma proporção que a produção.

A superprodução tem como base, por esse motivo, a circunstância de que a massa absoluta da produção cresce a uma taxa superior à taxa de consumo dos operários e capitalistas. Como afirma Marx (1980, p. 942), "não se trata de superprodução absoluta, superprodução em si confrontada com a necessidade absoluta ou com o desejo de possuir as mercadorias. Nesse sentido não existe superprodução parcial nem geral, e uma não se opõe mesmo à outra". O que há de mais estranho e paradoxal na superprodução, afirma Marx (1980, p. 942), consiste no fato de que "os verdadeiros produtores das mesmas mercadorias que congestionam o mercado carecem delas. Não se pode dizer aí que deveriam produzir as coisas para obtê-las, pois as produziram e apesar disso não as obtiveram".

Assim, a superprodução tem como princípio a existência do trabalho em sua forma assalariada, da produção capitalista como uma produção pela produção, da existência de uma classe de exploradores que não produz para si própria, mas, sim, para a incessante e insaciável acumulação de capital. O que constitui o fundamento da superprodução moderna não é a falta de compradores para os produtos porque as necessidades sociais já estão plenamente satisfeitas, mas, sim, é a existência, de um lado, diz Marx (1980, p. 963), da “produção em massa apoiada na massa de produtores confinados no domínio dos meros meios de subsistência, e, de outro lado, os limites impostos pelo lucro do capitalista".

As determinações mais fundamentais da superprodução devem, então, ser buscadas nas próprias relações antagônicas entre capital e trabalho, ao nível da instância do consumo produtivo, ao nível da instância do consumo da força de trabalho que é, simultaneamente, a instância da produção da mais-valia. Nessa instância fica revelado que 
todo operário é, pela natureza do capitalismo, um produtor de excedentes para o consumo alheio, que a superprodução só ocorre porque o próprio operário não produz para satisfazer suas necessidades ou as necessidades sociais, mas, sim, porque aquilo que o operário verdadeiramente produz é mais-valia, a riqueza abstrata e sem-fim da acumulação capitalista.

Por isso, quanto mais se desenvolve a produção capitalista mais se aprofunda a possibilidade do mais-produto carecer de compradores. Quanto mais se desenvolve a produção capitalista mais se desenvolve o espírito capitalista por mais sobretrabalho e, assim, a contradição entre produção e consumo encontra uma base sólida para se expandir emanando da própria relação de trabalho capitalista, da contradição entre trabalho vivo e trabalho morto, entre jornada de trabalho necessária e excedente, entre trabalho pago e não pago, enfim, da contradição entre os produtores assalariados e os proprietários capitalistas dos meios e condições do processo de trabalho.

A necessidade de mais-trabalho e de uma jornada de trabalho excedente, seja na forma absoluta ou relativa, extensa ou intensa, é uma necessidade imanente ao capital, é uma necessidade que brota naturalmente das relações de produção capitalistas. Dessa forma, parece tornar-se compreensível que para Marx a superprodução não seja uma causa da crise, mas, sim, seu fundamento mais profundo. Como afirma ele (MARX, 1989, p. 17): “o fundamento último (der letzte Grund) de todas as crises reais é sempre a pobreza e a restrição ao consumo das massas em face do impulso da produção capitalista a desenvolver as forças produtivas como se apenas a capacidade absoluta de consumo da sociedade constituísse seu limite".

\section{0 problema da queda da taxa média de lucro}

Como sabemos, a seção III do Livro III de O capital - que trata da lei da queda tendencial da taxa média de lucro - é uma declaração crítica de Marx às concepções da economia política de Ricardo (1982), que apresentava as tendências de crise do capitalismo causadas pelo 
aumento de salários. Ricardo explicava a elevação dos salários, por sua vez, por outra causa anterior: a crescente queda na força produtiva do trabalho agrícola. Esta, por seu lado, possuía também sua causa precedente, o cultivo crescente de terras menos férteis e mais distantes dos centros de consumo, que, por sua vez, era causado pela expansão das necessidades sociais nas cidades, isto é, pela expansão da demanda, carro chefe do processo de acumulação na concepção de Ricardo. A necessidade crescente de se cultivar terras menos férteis e mais distantes dos centros de consumo levava à queda da força produtiva do trabalho, à elevação do preço do trigo, à elevação dos salários, à elevação da renda da terra que cabia ao proprietário fundiário, à queda na taxa de lucro e à paralisia da produção, isto é, à crise em razão de uma queda na taxa média de lucro.

Essa concepção de Ricardo esconde, na visão de Marx, a circunstância de que a queda na taxa de lucro vem sempre, e necessariamente, acompanhada de uma elevação, tanto da massa de mais-valia quanto, principalmente, da taxa de exploração do trabalhador pelo capital. Marx faz questão de criticar essa concepção causal de Ricardo porque, conforme já havia demonstrado nas seções I e II do Livro III de O Capital, o lucro é nada mais que a forma invertida e mistificada da mais-valia, e a taxa de lucro nada mais é do que a forma invertida e mistificada em que se apresenta, no nível da esfera sensível e da consciência vazia da burguesia e de seus economistas políticos, a taxa de mais-valia, a taxa de exploração do trabalhador. A taxa de lucro é nada mais do que uma forma, vazia de sentido em si mesma, em que se expressa ideologicamente a taxa de exploração do trabalhador pelo capital. Já nos Grundrisse, em uma passagem em que comenta a teoria de Ricardo sobre a queda da taxa média de lucro, Marx (1987, p. 99) fala literalmente dessa natureza fantasmagórica e enganosa do lucro: “o lucro é somente uma forma transmutada, derivada e secundária da mais-valia, a forma burguesa em que se tem borrado as marcas de sua gênese", diz ele.

Se o lucro e a taxa de lucro são a forma mistificada da mais-valia e da taxa de mais-valia ao nível da realidade sensível, aparente e imediata do mercado, a queda na taxa de lucro é, então, de maneira ainda mais mistificada, a forma de manifestação invertida do aumento da 
taxa de mais-valia. E não somente do aumento da taxa de mais-valia, mas, inclusive e simultaneamente, da massa de mais-valia produzida pelo conjunto da classe trabalhadora a fim de prover a insaciável voracidade do capital por mais sobretrabalho. A queda da taxa média de lucro - ou seja, a queda relativa da massa de mais-valia total em relação ao capital global - esconde todas as determinações essenciais em que se fundamenta a crise e a acumulação capitalista: aumento absoluto da massa de mais-valia, aumento absoluto da taxa de exploração sofrida pelos operários, aumento absoluto da força produtiva do trabalho, aumento absoluto da riqueza em sua forma abstrata em mãos cada vez mais concentradas de um lado; e, de outro, aumento cada vez mais absoluto da pobreza no polo que produz essa riqueza.

Porque a taxa média de lucro e sua queda na crise escondem todas as determinações mais internas e fundamentais do capital, Marx não se cansa de dizer que ela é apenas uma forma mistificada e enganosa de manifestação, sob bases capitalistas, do crescimento absoluto da produtividade do trabalho social, do crescimento absoluto da massa de riqueza produzida e do crescimento absoluto da exploração no interior da classe operária. Marx insiste em afirmar, por isso, que a queda na taxa de lucro é, então, como a superprodução, um mero fenômeno que precisa se criticado. Quando Marx expõe a lei da queda tendencial da taxa média de lucro nunca a apresenta, portanto, como causa da crise, mas, sim, como a forma de manifestação de algo mais fundamental e não perceptível imediatamente aos nossos sentidos. Desse modo, a queda na taxa de lucro não é, junto com a superprodução e outros fenômenos, uma causa da crise, mas, sim, "uma expressão peculiar (ein eigentümlicher Ausdruck) ao modo de produção capitalista para o desenvolvimento progressivo da força produtiva social do trabalho", diz Marx (1989, p. 155).

Também o progressivo decréscimo relativo do capital variável em relação ao capital global - em outras palavras, o aumento da composição orgânica do capital, aumento que está na base da queda da taxa de lucro - "é igualmente apenas outra expressão (nur ein anderer Ausdruck) para o progressivo desenvolvimento da força produtiva social do trabalho" (MARX, 1989, p. 155). Diz ainda Marx (1989, p. 
173) que tanto a elevação da taxa de mais-valia quanto a queda da taxa média de lucro "são apenas formas específicas em que se expressa de maneira capitalista a crescente produtividade do trabalho (sind nur besondere Formen, wohin sich wachsende Produktivität der Arbeit kapitalistisch ausdrückt)". Diz ainda mais uma vez Marx (1989, p. 157): “o decréscimo proporcional do capital variável e o aumento do capital constante, embora ambas as partes cresçam absolutamente, é, como se disse, apenas outra expressão (nur ein andrer Ausdruck) para a produtividade aumentada do trabalho".

\section{A produção pela produção como meta absoluta do capital}

Como já dissemos na introdução, não pretendemos neste curto espaço mostrar todo o complexo problema expositivo da teoria da crise de Marx em O capital. Pretendemos apenas mostrar - a partir da análise da superprodução, do subconsumo e da queda tendencial da taxa de lucro - que as chamadas causas da crise exploradas pelos diferentes comentadores não passam, para Marx, de meras formas de manifestação de contradições ocultas da produção capitalista que precisam ser denunciadas.

O que se esconde por trás da queda da taxa de lucro, da superprodução e do subconsumo das massas - os fenômenos fundamentais da crise - é a crescente luta da classe capitalista pela elevação da produtividade do trabalho social e pela ampliação absoluta da massa global de mais-valia disponível para ser repartida entre todos os diferentes capitalistas individuais. A questão central seria, então, do ponto de vista de Marx, explicar de onde emanam essa luta e essa necessidade de ampliação constante da massa absoluta de mais-valia.

Segundo Marx, a meta absoluta da produção capitalista não é apenas a produção e a apropriação de mais-valia por parte dos capitalistas individuais. A meta absoluta do sistema não é a de garantir que cada parcela individual do capital social se aproprie anualmente de uma massa de mais-valia que lhe assegure um rendimento médio anual idêntico ao rendimento de seus irmãos rivais e ao rendimento 
obtido nos anos anteriores. A meta absoluta do regime capitalista em seu conjunto é fundamentalmente a permanente ampliação da massa absoluta de mais-valia disponível para ser repartida entre as diferentes parcelas individuais do capital global. A meta absoluta do sistema é garantir que ano após ano a multidão de capitalistas individuais espalhada pelos diferentes pontos do mercado mundial se aproprie de uma massa maior de mais-valia empregando a mesma massa de capital empregada no ano anterior.

Essa ampliação absoluta da massa global de mais-valia só pode ser alcançada, contudo, mediante métodos que aprofundam cada vez mais as contradições do conjunto do sistema, mediante métodos que em seu conjunto opõem-se, contraditoriamente, à valorização sem-fim do valor. Essas contradições, então, periodicamente explodem na crise levando o sistema à sua autodestruição inevitável.

Para que a massa absoluta da mais-valia global possa aumentar continuamente, os capitalistas individualmente e em seu conjunto devem funcionar no sistema como meros agentes da produção - e nunca do consumo -, como meros funcionários ou servos da acumulação sem-fim de capital. Cada capitalista individual, e mesmo a classe capitalista em seu conjunto, deve atuar no interior do sistema - como de fato atua - como agente não de suas próprias paixões e impulsos pessoais, mas, sim, como agente das paixões e impulsos do capital, da produção pela produção, da produção como mero meio para ampliar ainda mais a produção já realizada sem nenhuma consideração imediata pelo consumo e pela satisfação humana - seja esse consumo e essa satisfação da classe capitalista ou da classe operária.

Para que essa meta absoluta seja atingida, todos os poderes da ciência e do trabalho terão, então, que ser cotidianamente postos em atividade pela classe capitalista para ampliar cada vez mais a produtividade do trabalho social e a exploração do conjunto da classe trabalhadora. Todos os formidáveis poderes da ciência e da mecânica serão postos pela classe capitalista, assim, para ampliar a produção a níveis sempre maiores ano após ano. Ao mesmo tempo, e paradoxalmente, todos os poderes do capital serão usados para restringir não apenas o consumo da classe capitalista, mas, sobretudo, o consumo do conjunto 
da classe operária. Ao mesmo tempo em que todos os poderes da produção serão empregados para a contínua ampliação da riqueza disponível anualmente, o consumo do conjunto da sociedade - da classe capitalista e operária em seu conjunto - será continuamente restringido e limitado a níveis sempre menores tanto relativa quanto absolutamente. Assim, movida por dois impulsos contraditórios - sobre os quais a classe capitalista em seu conjunto não possui nenhum controle - a sociedade capitalista vai lentamente dirigindo suas forças para a crise e para sua autodestruição inevitável.

A crise e a autodestruição do sistema em seu conjunto são inevitáveis porque não há nenhuma força no interior do sistema - e muito menos fora dele - capaz de conter os impulsos contraditórios da acumulação capitalista e suas desastrosas consequências. Para poder reequilibrar-se e manter suas potências contraditórias em ação, o capital global da sociedade tem, então, de eliminar parte excedente de seus próprios membros individuais lançando-os na falência e na destruição. Para que o conjunto do capital global seja preservado, muitos capitais individuais excedentes deverão, por isso, ser destruídos. E com a destruição desses membros excedentes será destruída simultaneamente aquela parte da riqueza excedente produzida que abarrota o mercado e não encontra compradores. A destruição de capital excedente virá acompanhada, por isso, pela retração abrupta da produção industrial e pelo desemprego generalizado de trabalhadores em todos os setores da sociedade.

\section{A superação positiva da crise e da sociedade capitalista}

Com a crise e a destruição de capital que se segue abre-se, desse modo, um caminho, até então bloqueado pelas energias do sistema, para a superação positiva da sociedade capitalista. Com a iminente possibilidade de destruição da sociedade - e especialmente da destruição das condições cotidianas de vida da classe trabalhadora provocada pelo desemprego em massa e pela redução geral de salários - abre-se então a possibilidade de uma atuação massiva e explosiva do conjunto 
da classe trabalhadora mundial sobre a agonia mortal do sistema. Sem nada mais a perder - pois a crise já lhe arrancou todas as expectativas ilusórias sobre o sistema - abre-se a possibilidade de uma ação revolucionária da classe trabalhadora sobre os destinos da sociedade. De mera condição subjetiva para o trabalho e força de produção para o capital, a classe trabalhadora se converte, então, em força revolucionária para si mesma e para o futuro.

A crise é a irrupção de um abismo que se põe inusitadamente no caminho do ser-capital. Abismo posto, contraditoriamente, pelo próprio capital. A crise é a abertura de um caminho para o futuro. A crise é a abertura de uma via que estava fechada pelo ser-capital durante a fase de curta prosperidade, e uma abertura para a via do não ser da revolução operária, da economia planificada e do socialismo. A crise do capital, na verdade, é uma abertura inesperada para o futuro e para a verdadeira história da humanidade. A crise é um caminho, porém, que só poderá ser percorrido se o proletariado, no curso do período que a antecede, ou mesmo durante ela, resolver sua trágica ausência de direção, da direção que conhece e aponta o caminho da superação da sociedade, da direção que do interior da classe operária a conduz em direção da tomada revolucionária do poder. Com a crise abrem-se, por isso, os portões para a intervenção das verdadeiras forças e organizações socialistas, daquelas forças que acreditam no futuro e no potencial revolucionário e emancipatório da classe trabalhadora mundial.

Com a revolução, o colapso da sociedade capitalista daria lugar ao socialismo e a uma nova fase no desenvolvimento das forças produtivas. Com a revolução socialista teria chegado, por isso, o fim da propriedade privada, da crise, da superprodução, da anarquia do mercado e da produção pela produção. As forças produtivas do trabalho social poderiam, então, ser agora libertadas das relações burguesas de produção. Chegaria, assim, a hora da economia planificada e da dissolução positiva da sociedade capitalista.

Se o caminho que se abre não é, porém, percorrido pela classe trabalhadora e por suas direções revolucionárias, a destruição de capital e a depressão reconstroem a via da sociabilidade burguesa, reconstroem a unidade que se dissolvera, e se continua, então, a percorrer, como se 
tem percorrido até agora, o caminho da barbárie, o caminho da aliança entre os sofistas do movimento socialista - criadores de farsas e ilusões dentro da classe trabalhadora - e o ser-capital.

Sem revolução e com a restauração do sistema, as forças produtivas capitalistas seriam lentamente destruídas ao longo do tempo por suas próprias contradições internas e por crises cada vez mais profundas e costumeiras. Sem revolução, todas as conquistas da modernidade burguesa poderiam ser, então, destruídas no palco das guerras comerciais e militares, cada vez mais violentas e insanas.

\section{Referências}

MARX, K. Teorias da mais-valia. São Paulo: Difel, 1980.

MARX, K. Elementos fundamentales para la crítica de la economia política: borrador. 1857-1858. México: Siglo Veintiuno Editores, 1987.

MARX, K. O capital. São Paulo: Abril Cultural, 1989.

RICARDO, D. Princípios de economia política e tributação. São Paulo: Abril Cultural, 1982.

Recebido: 10/06/2010

Received: 06/10/2010

Aprovado: 08/05/2011

Approved: 05/08/2011 